\title{
CLIWOC: A CLIMATOLOGICAL DATABASE FOR THE WORLD'S OCEANS 1750-1854
}

\author{
R. GARCÍA-HERRERA ${ }^{1}$, G. P. KÖNNEN² ${ }^{2}$, D. A. WHEELER ${ }^{3}$, M. R. PRIETO ${ }^{4}$, \\ P. D. JONES ${ }^{5}$ and F. B. KOEK ${ }^{2}$ \\ ${ }^{1}$ Dto. Física de la Tierra II, Facultad de Físicas, Universidad Complutense de Madrid, \\ Ciudad Universitaria, 28040 Madrid, Spain \\ E-mail: rgarciah@fis.ucm.es \\ ${ }^{2}$ Royal Netherlands Meteorological Institute (KNMI), PO Box 201, 3730 AE De Bilt, \\ The Netherlands \\ ${ }^{3}$ School of Health, Natural and Social Sciences, University of Sunderland, Green Terrace, \\ Sunderland SR1 3PZ, U.K. \\ ${ }^{4}$ Instituto Argentino de Nivología y Glaciología, Calle A. Ruiz Leal s/n, 5500 Mendoza, Argentina \\ ${ }^{5}$ Climatic Research Unit (CRU), University of East Anglia, Norwich NR4 7TJ, U.K.
}

\begin{abstract}
We have compiled a meteorological database over the world's oceans by digitizing data from European ship logbooks of voyages in the period 1750-1854. The observations are carefully reviewed and transformed into quantitative data. The chief contents of the database are wind direction and wind force information, from a period without standardized scales. It is found that the information content of these so-called non-instrumental data is much higher than previously believed. The 105year CLIWOC database extends existing meteorological world ocean databases like ICOADS back in time by a full century.
\end{abstract}

\section{Introduction}

The existing meteorological world databases, for example the Jones land database (Jones, 1994) and the Comprehensive Ocean-Atmosphere Data Set (COADS; Woodruff et al., 1987; Elms et al., 1993; Worley et al., 2005; recently renamed I-COADS (Diaz et al., 2002) and subsequently ICOADS (Parker et al., 2004), the I standing for International), basically extends back to 1854, which is the first year after the 1853 Brussels Conference that initiated standardization of meteorological observations (Quetelet, 1854). Data taken prior to that conference are generally considered to be of inferior value, owing to lack of standardization of the observation practices and because of the increasing lack of instrumental observations of parameters such as temperature and pressure if one proceeds backward in time. Illustrative of this is the fact that, although the ICOADS Release 2 and 2.1 (Woodruff et al., 1998; Worley et al., 2005) extends back to the early 1800 s by blending with the US Maury collection (Woodruff et al., 2005), no serious attempts have been undertaken so far to integrate the pre- and post-1854 contents of this database.

In view of the increasing interest in low frequency climate variability (Houghton et al., 2001), the length of the existing standard databases ( $\sim 150$ year) is rather short. 
This motivated us to explore the real information content of a pre-1854 database over the world's oceans, based on the data that were routinely taken on board of every ship on a daily basis. In the framework of the 3-year EU project CLIWOC (Climatological Database for the World's Oceans 1750-1850), we have compiled a world's oceans database (back to 1750) by digitizing the data from logbooks of pre-1854 voyages of English, Spanish, Dutch and French ships. In conjunction with this, a 'dictionary' was developed to translate the archaic wind force terms from the four languages into Beaufort equivalents (CLIWOC Team, 2003). This dictionary is included in the database as a dynamic module, to facilitate its updating. Our conclusion is that the CLIWOC database is well able to produce indices of largescale variability, such as North Atlantic Oscillation (NAO) and Southern Oscillation Index (SOI), and therefore represents a meaningful backward extension of world climatological oceanic databases such as ICOADS.

\section{Organization and Scope of the CLIWOC Project}

CLIWOC was carried out by partners from three European countries: Spain, UK, and The Netherlands. Additionally, a partner from Argentina was involved. The project coordination was undertaken by the Spanish partner. CLIWOC aimed to determine the value of the meteorological information in pre-1854 ship logbooks for climate studies. A database was compiled using English, Dutch and Spanish logbooks; a logical choice given the colonial pasts of these nations. No French partner could be found, but 20 French logs were obtained and included in the database. Portugal, another seemingly obvious source of logbooks, was not involved, as logbooks from the period after 1755 could not be located while their pre-1755 nautical archive was lost in the great earthquake and subsequent fires.

In the three partner countries, the logbooks were generally found in national archives and libraries, having sometimes luckily survived destruction. The locations of the logbooks were carefully documented prior to processing. The Spanish, Dutch and English logbooks were processed in the respective countries; processing of the French logbooks was mainly performed by the Spanish and Argentinean partners. A few published logbooks from the USA, Germany and Denmark, found in the Dutch archives, were also digitized by the Dutch. In the last stage of the project, the Dutch partner also processed two Swedish logbooks from $\sim 1750$ with unique daily temperature readings (see, for details, García-Herrera et al., 2005).

In the set-up of the project, we made the following four choices. First, we aimed for data density rather than going back in time as far as possible. Initially, the CLIWOC period was fixed at 1750-1850, later the Dutch partners extended the period to 1854 , to bridge the gap with Release 1 (Woodruff et al., 1987) of ICOADS. Second, we mainly digitized noon observations, even where the logbooks contained sub-daily data. The motivation was that noon observations in general contain much more meteorological information, and the ship position was only 


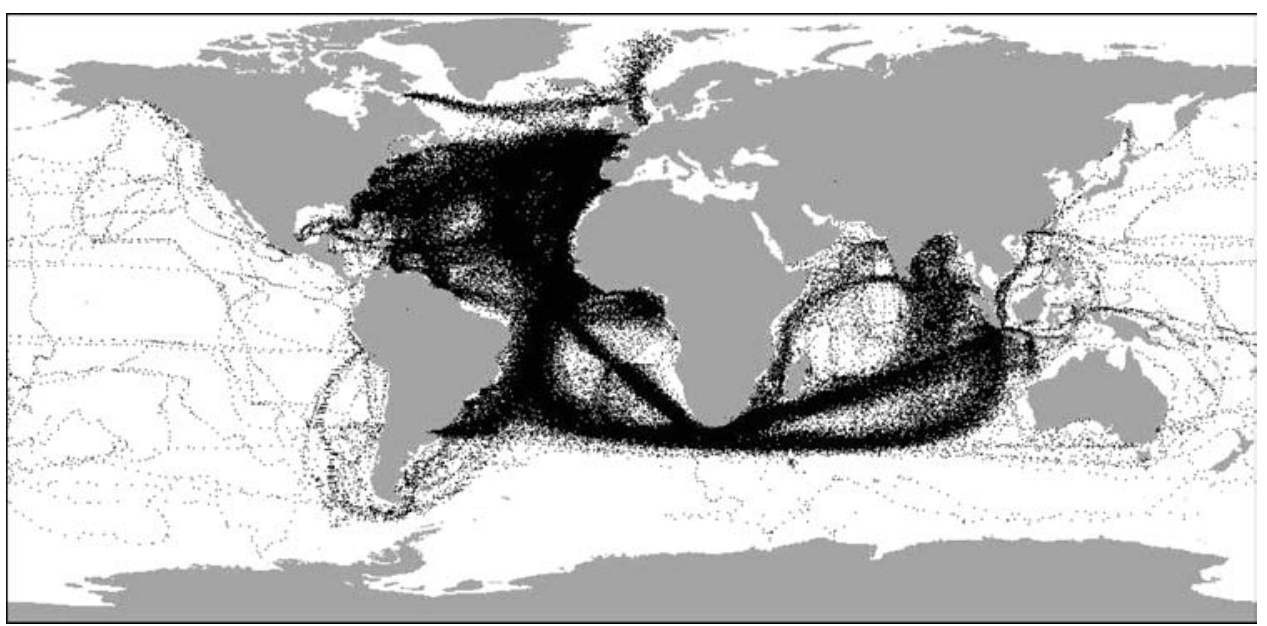

Figure 1. Spatial distribution of the data included in CLIWOC, 1750-1854.

recorded at noon. Third, we included only data from voyages from the open oceans, ignoring logbooks from journeys in inland seas like the Baltic or the Mediterranean. Fourth, we optimized the temporal distribution of digitized data and aimed for as wide a spatial coverage as possible. This was done by pre-selecting voyages from the huge amount of logbooks available in the UK.

Although the database was in principle designed to serve climate studies, we added to the database recorded information of events on board in order to support other studies by e.g. historians. Despite the significant resources that it took, we felt it worthwhile to design a database for multidisciplinary use (see Wilkinson, 2005). Furthermore, we linked, as far as possible, the database to digital images of the logbook pages, allowing direct access to the original data (www.ucm.es/info/cliwoc).

Figure 1 shows the spatial distribution of the ship observations of CLIWOC. The Atlantic and Indian oceans are well covered; the Pacific is, however, largely devoid of observations. Due to the different colonial interests, the spatial coverage varies between the countries. The temporal coverage, depicted in Figure 2, shows that the data are more or less evenly distributed in time, although political factors (e.g. Napoleonic wars) cause numbers to fluctuate in certain areas and times, with a minimum for the period 1805-1835 (see, for more details about these figures, Können and Koek, 2005).

\section{Nature and Contents of Pre-1854 Ship Logbooks}

Weather observations in pre-1854 ship logbooks were taken with an almost military routine. Even from the beginning of the great voyages in the 16th century, the positions and weather observations were taken every day. From the 17th century onwards, the observations were in tabular form. With this perspective, it is hardly 


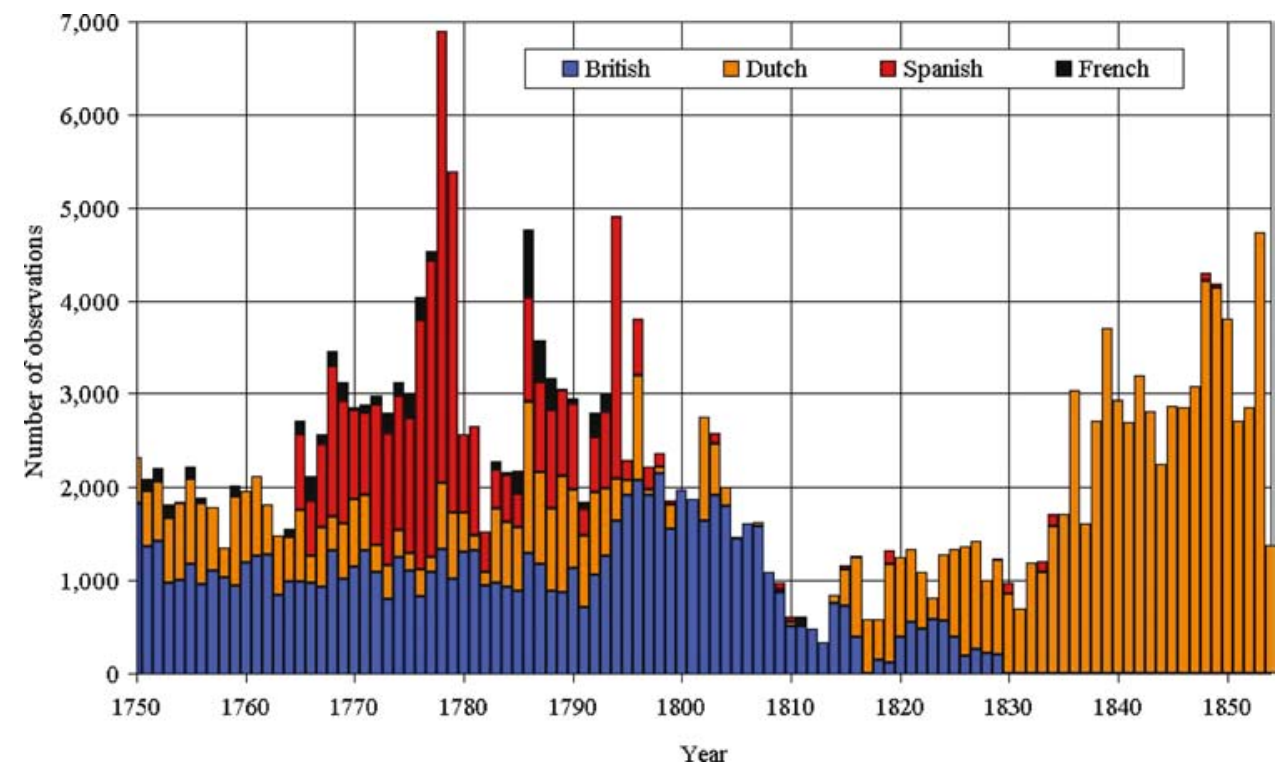

Figure 2. Annual number of observations included in CLIWOC by country.

surprising that the initiative for the 1853 Brussels conference (Quetelet, 1854) on standardization of meteorological observation was taken by navy officers rather than by professional meteorologists. Details about the evolution of the logbooks are given in García-Herrera et al. (2005).

The meteorological content of the CLIWOC logbooks consists of the date, geographical position, wind direction, wind force, present weather, sea state, sea ice reports and, starting from the turn of the century, temperature and air pressure. Nowadays, wind direction and non-anemometer wind force estimates from ships are usually regarded as 'non-instrumental', but we contest this terminology. The meteorological content of systematic wind observations from ship logbooks is superior to proxy data, since the directional observations are not done without at least a compass. Such data might better be called 'semi-instrumental'. Even wind speeds could be referred to as such, the sails being the 'instruments' (see e.g. Koek and Können, 2005). Basically the methods by which wind direction and wind force estimates were made at sea did not change until the introduction of reliable ship anemometers and wind direction recorders, which happened only well into the 20th century. Hence, 18th century practice was as sophisticated as in most of ICOADS data. The only real difference in the pre-1854 data is the use of other wind force scales and non-standard terminologies.

Figures 3 and 4 show the fraction of observations that includes instrumental data in the strict sense, i.e. of air temperature and pressure. Significant values start basically around 1800 . The very early temperature readings all originate from the two Swedish logbooks processed in CLIWOC (Können and Koek, 2005). The 


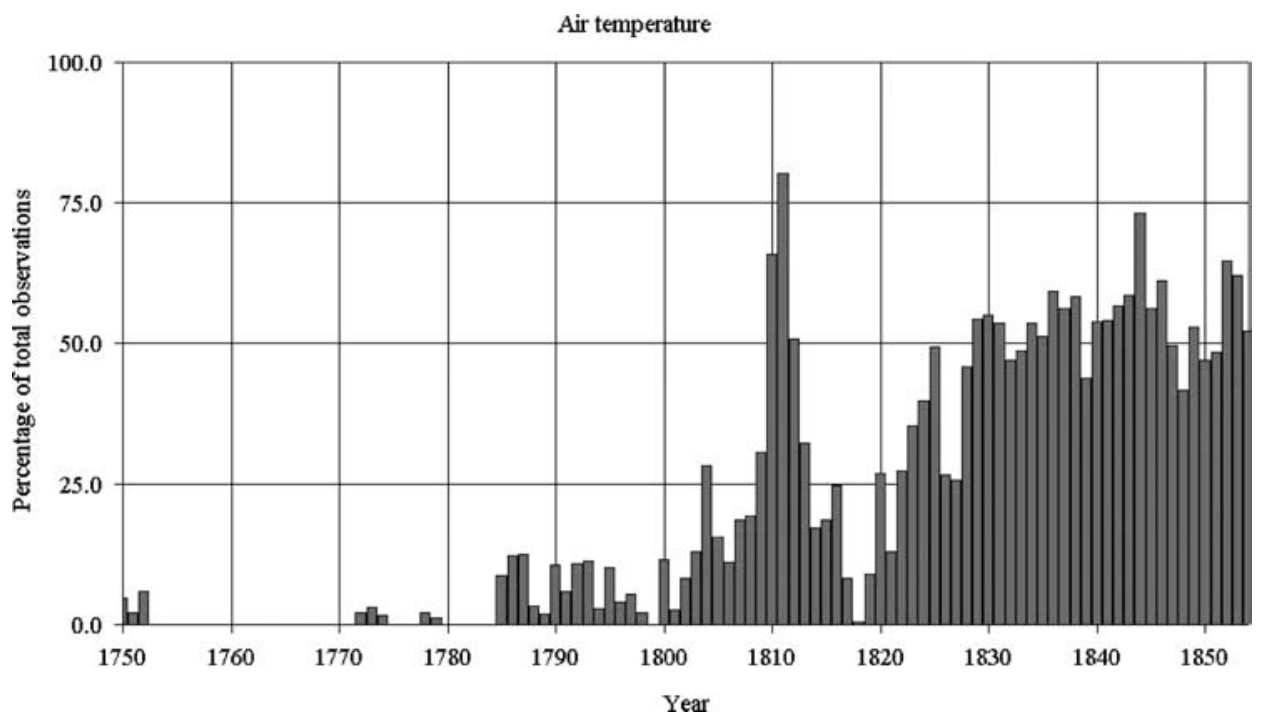

Figure 3. Fraction of CLIWOC observations that includes air temperature.

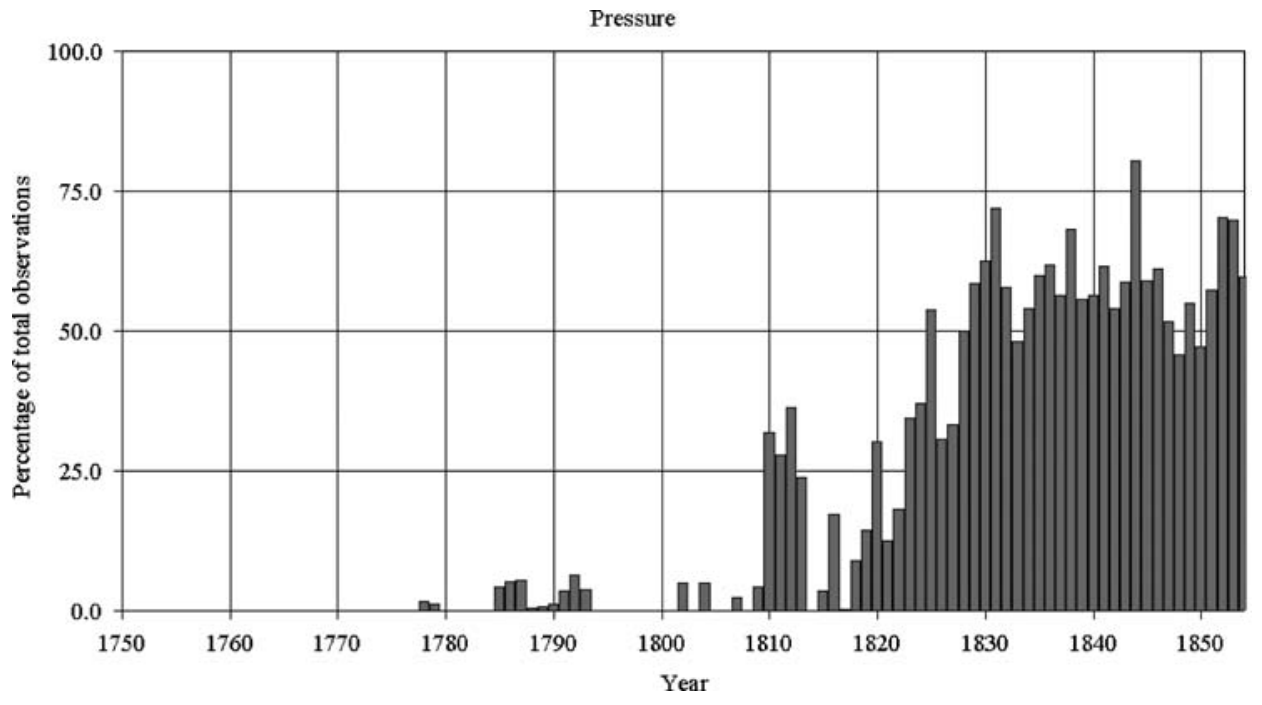

Figure 4. Fraction of CLIWOC observations that includes pressure.

curves stabilize at $\sim 60 \%$ for both variables. This seems a prelude to the Brussels standardization (Quetelet, 1854); note that $60 \%$ of the ICOADS data (US Maury collection excluded) 1854-1880 include pressure observations, and more than $90 \%$ include temperature. However, pre- and post-1854 instrumental data are not easily combined, as in the early period, for example, only rarely a thermometer was attached to the barometer, and height corrections to pressure were probably not applied. On the other hand, one can be quite confident that most of the pressure 
readings came from mercury barometers, as the aneroid barometer came only to full development in the late 1840s (Middleton, 1964).

In the post processing of the data, we concentrated on date, time, position, wind direction and wind force taken at local noon. Pressure and temperature, although included in digital form in the CLIWOC database (see Können and Koek, 2005), are not exhaustively quality checked. No serious attempts were made to uniformly interpret the 32,000 archaic present-weather or the 8,300 different sea state description terms. They are, however, available from the database and a section of the dictionary (CLIWOC Team, 2003) is devoted to the translation of Spanish archaic sea state terms into their modern equivalents.

\section{Data Processing, Quality Checks, Data Accessibility}

After keying the data and making direct checks for typing errors by re-keying 5\% of the data, all ship trajectories were scrutinized for breaks caused by transitions of zero meridians. These transitions were usually initiated by a new land sighting. No less than 646 zero meridians were identified. All positions were corrected to present-day coordinates, the end of the track adjusted to the actual position of the port of destination, after which the ship positions were adjusted along the track to correct for the accumulated error in the longitude determination (see, for details, Können and Koek, 2005).

The post processing of the meteorological elements temperature and pressure was only basic. Temperatures were converted to Celsius while pressure readings were converted to $\mathrm{hPa}$ and reduced to standard gravity, after which the data were subjected to coarse range checks. Neither a reduction to $0{ }^{\circ} \mathrm{C}$ nor a correction for the height above the sea surface was applied to the pressure readings.

The core of the activities concerning the quality checks involved the wind. It consisted of four steps. In the first one, the wind force terms were scrutinized. In total 3,550 of them were found. Some 1,650 were used frequently enough to allow for translation into Beaufort (sub)classes; the remaining 1,900 were not considered in the analysis. These comprise, however, less than $1 \%$ of all observations. The Beaufort scale used for the translation was the WMO code 1100 scale (WMO, 1947). The translation was based on linguistic, nautical as well as on historical information. The translation into a modern wind scale was performed in the country were the logbooks originated from; the French task was performed by the Spanish and Argentinean teams. See, for details, Prieto et al. (this volume), Wheeler and Wilkinson (this volume), and Koek and Können (2005); see also CLIWOC Team (2003).

In a second and more advanced quality check, the reliability of the wind force and direction determinations were tested. Intra-nationally this was done by comparing observations among several ships traveling in convoy; inter-nationality comparisons were made during encounters between ships of different countries (see, for details, Wheeler, 2005). 
The third quality check was a comparison of CLIWOC 1750-1854 monthly vector wind components (U, V) climatology with ICOADS 1961-1990. The evaluation yields only small differences between modern and CLIWOC data, adding confidence to the methods of converting the original CLIWOC wind data into Beaufort scale numbers. Some seasonal characteristics are clearly apparent in the data (e.g. the Monsoon cycle). See, for details, Jones and Salmon (2005).

As a last step, the quality of wind directions was improved by investigating whether they referred to the magnetic or the true north. This was done by means of a comparison between CLIWOC and ICOADS wind direction climatology in a region where the magnetic variation is large. In the case of English logbooks, there was also documentary evidence that could be called upon to solve the question (see, for details, Können and Koek, 2005; Wheeler, 2005).

After these checks and improvements, the data were put into IMMA format (Woodruff, 2004) and entered in the database. In November 2003, the CLIWOC database was put on the Internet as Release 1.0. The first climatological analyses (Jones and Salmon, 2005) are based on a second version, Release 1.1 (GarcíaHerrera et al., 2004). The final version in the framework of the EU CLIWOC project is Release 1.5 (see, for details, Können and Koek, 2005).

\section{First Scientific Results and Potential Applications}

The first scientific studies with CLIWOC concerned a search for signals of the North Atlantic Oscillation (NAO) and Southern Oscillation Index (SOI) by means of regression with principal components of wind fields. The method worked well and the signal to noise ratio in $8^{\circ} \times 8^{\circ}$ grid boxes was high enough to allow for reconstructions over the entire period 1750-1854. Even with the current CLIWOC density, the reconstruction of NAO from the North Atlantic data for the December-March season proved to surpass the quality of proxy record reconstructions. Similarly, the Indian Ocean data for the October-March season allows for a SOI reconstruction 1750-1854. This result opens broad perspectives for backwards extension of the SOI, recovering both El Niño and La Niña events by a full century or more from the available semi-instrumental data recorded by ships (see, for details, Jones and Salmon, 2005).

With these results the original goal of CLIWOC, that of exploring the real information content of a pre-1854 database over the world's oceans using data that were routinely taken on board every ship on a daily basis, is met. It can be concluded that the quality of the CLIWOC data is good enough to allow for meaningful climate studies. Many possibilities arise. For instance, a casual glance at Figure 1 shows that Africa is surrounded by ship observations, and the same holds for the east coasts of the Americas. Following an idea earlier formulated by Frydendahl et al. (1992) with regard to Denmark, CLIWOC may make it possible to reconstruct circulation patterns over land masses such Africa and South America, in a period 
where virtually no land stations existed. CLIWOC data can also be used to study extreme climatic occurrences, such as the low latitude sightings of icebergs, as can be seen in Prieto et al. (2004). However, the real strength of the CLIWOC database may become clear only after blending with ICOADS, which will provide a database over the world's oceans over the entire 250-year period 1750-2000.

\section{Review of Other Marine Data for 1750-1854}

Even upon completion of the CLIWOC project, marine data for the period 17501854 are not fully digitized. Table I shows the current situation regarding the data involved in the project. Particularly in the UK, and to a lesser degree in France, there is a vast amount of undigitized data available. If all these data were included in CLIWOC, the database would expand by a factor of about six.

There exist two other databases with pre-1854 observations. The first one is the US Maury collection (Woodruff et al., 2005), which covers the period 17841863 , starting to become significant after 1800 . After 1820 , its yearly number of observations surpasses the average 3,000-level of CLIWOC; the collection peaks at almost 55,000 ship-day observations in 1853 (see Figure 5). All US Maury data are keyed (see Table I), the collection being integrated in ICOADS Release 2 (Woodruff et al., 2005). Although the keying included sub-daily observations also, there are only very few pre-1854 logbooks that included observations at hours other than noon. In that respect the US Maury and CLIWOC databases are comparable. The geographical coverage of the US Maury data is similar to that of the UK data in CLIWOC. However, the wind force and wind direction in the US Maury collection are still in the descriptive form only; no attempt has been made to systematically convert the terms into Beaufort scale equivalents.

TABLE I

Number of data in the CLIWOC (Release 1.5) database and in the US Maury collection, and in the $1854-1870$ period of ICOADS

\begin{tabular}{lllllll}
\hline & Main period & Keyed data & $\begin{array}{l}\text { Data/yr } \\
(\mathrm{k})\end{array}$ & $\begin{array}{l}\text { Available } \\
(\mathrm{M})\end{array}$ & $\begin{array}{l}\text { Exhaustion } \\
(\%)\end{array}$ & $\begin{array}{l}\text { Data/yr if } \\
\text { exhausted (k) }\end{array}$ \\
\hline CLIWOC/Spanish & $1750-1800$ & $0.05 \mathrm{M}$ & 1 & 0.05 & 100 & 1 \\
CLIWOC/Dutch & $1750-1854$ & $0.13 \mathrm{M}$ & 1.3 & 0.3 & 50 & 3 \\
CLIWOC/UK & $1750-1850$ & $0.09 \mathrm{M}$ & 0.9 & 1.8 & 5 & 18 \\
CLIWOC/French & $1750-1850$ & $10 \mathrm{k}$ & 0.1 & 0.2 & 5 & 2 \\
CLIWOC/ALL & $1750-1854$ & $0.3 \mathrm{M}$ & 3 & 2.3 & 12 & 23 \\
US Maury & $1830-1859$ & $1.0 \mathrm{M}$ & 33 & 1.0 & 100 & 33 \\
ICOADS & $1854-1870$ & $0.2 \mathrm{M}$ & 12 & 0.2 & 100 & 12 \\
\hline
\end{tabular}

Note. All values are reduced to number of ship-day observations.

${ }^{\mathrm{a} E x c l u d i n g}$ the US Maury collection. 


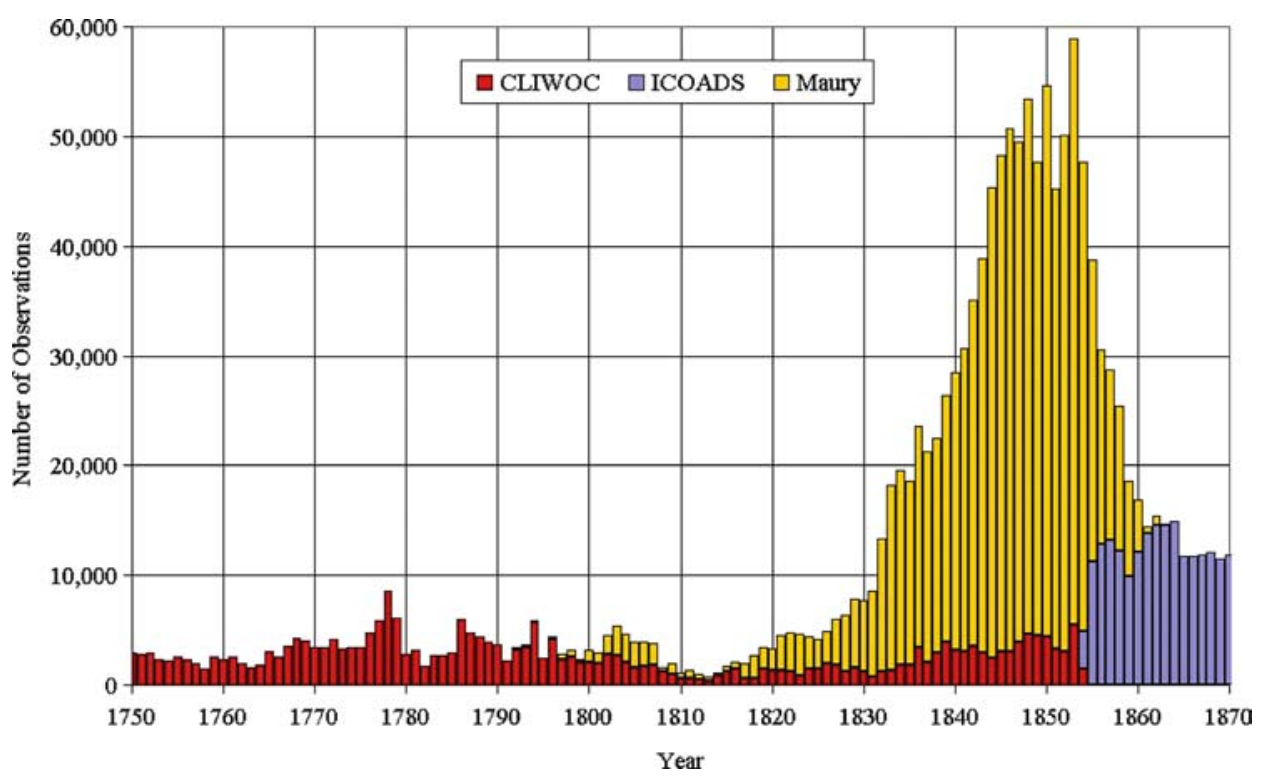

Figure 5. Annual number of observations in CLIWOC, ICOADS (without US Maury) and the US Maury collection, 1750-1870. All values are reduced to number of ship-day observations.

The second pre-1854 database is from Denmark, 1675-1715, hence pre-dating the CLIWOC period (Frydendahl et al., 1992). In contrast to CLIWOC this database was especially designed for one purpose, i.e. to reconstruct of the daily wind climate over Denmark. If the numbers are reduced to the number of ship-day observations, the Danish database consists, apart from lighthouse data, of about 120,000 observations extracted from ship logbooks. However, only ship observations from the seas surrounding Denmark were processed.

The situation regarding the availability of 1750-1854 data over the world's oceans, other than those mentioned above is not in all respects clear. It seems that the Danish undertook in the CLIWOC period regular voyages to Iceland and the West Indies of which many logbooks survived (Frydendahl et al., 1992). So far, no plans exist to digitize these documents. As mentioned, little is left from Portugal. Germany operated for a while from Oostende (Belgium), but so far few logs for the CLIWOC period have been located. Table I, together with the information summarized in the above paragraphs can be considered as a first step to a comprehensive inventory of ship log availability for $1750-1854$.

\section{CLIWOC versus ICOADS}

Figure 5 compares the CLIWOC annual observations with the ICOADS data, separated into the US Maury data and the other ICOADS data. Disregarding the Maury data set, the ICOADS data consists for the 1854-1870 period almost entirely 
(>90\%) of observations from Dutch vessels (Wallbrink et al., 2003). In order to make a clear comparison between the numbers of observations, the quantities are, as in Table I, reduced to number of ship-day observations per year, i.e. multiple observations from a ship on one day are counted as one ship-day observation. Compared with the COADS Release 1c plot (Woodruff, 2001), this reduces both the amounts of ICOADS and the post-1853 US Maury data by a factor of five; the pre-1854 US Maury data are hardly affected.

The following two features are apparent. First, the 1854 transition from CLIWOC to ICOADS results in an increase by a factor of 4 , from about 3,000 to 12,000 ship-day observations per year. This indicates that signals derived from the CLIWOC database would have a standard error that is roughly two times larger than those derived from early ICOADS. In that sense CLIWOC represents a meaningful backward extension of ICOADS. Further digitization of the European data (Table I) would result in CLIWOC annual numbers surpassing those of the early ICOADS period. Second, the US Maury data produces a notable peak in the $1850 \mathrm{~s}$ in the combined ICOADS/CLIWOC graph; a casual glance at the ICOADS plots (Woodruff et al., 1998) reveals that this level is not reached in ICOADS until the late 1880s, where the non-Dutch contributions becomes substantial. See, for details about the US Maury collection and 19th century ICOADS Woodruff et al. (2005).

\section{Conclusion of the CLIWOC Project and Further Work}

With the completion of the EU-funded CLIWOC project we have shown that a pre1854 and wind-only database possesses an information content that is much greater than was generally believed. It is able to reveal large-scale patterns of variability, like NAO and SOI, and offers a number of additional possibilities. This refers not only to climatic studies, but also to studies from other disciplines, like history. The present design of the database allows for large-scale climatic studies as well as for more narrowly-focused case studies.

Complete assimilation of the CLIWOC information may take years. It is clear, however, that integration with existing databases such as ICOADS would enhance the value of the data.

Given the fact that the usefulness of this type of database seems to be established now, it is worthwhile considering the next steps. A first priority is to enhance the density of data over the 1750-1854 period. This can be done by digitizing the ship logs that were not processed in CLIWOC (Table I), in particular those from UK, and by searching for and digitizing logs from Denmark and, perhaps, other European countries. A shorter-term activity would be post-analyzing the wind data of the US Maury collection, which are already digitized, in order to make them compatible with CLIWOC. A successful completion of such a project would add 1 million to the 0.3 million CLIWOC data (Table I), although mainly concentrated in the last quarter of the century covered by CLIWOC. 
Because systematic observations exist from the early 17th century onward, a further logical extension of CLIWOC would be the inclusion of pre-1750 data. A casual inventory suggests that backward extension with the available data from Europe from 1700 or perhaps even from 1650 onwards would result in sufficient data coverage to allow for meaningful reconstruction of the NAO and perhaps even the SOI with far more detail than obtainable from proxy records. It is an intriguing thought that in this way a 350-year database could be compiled from data written down in ship logs by our distant ancestors, who could never have dreamed of the intrinsic value of all their painstakingly prepared records.

\section{Acknowledgments}

This work was supported by the European Commission, DG XII, Programme 2.4.1: 'Better exploitation of existing data and adaptation of existing systems', EC Framework V Project EVK2-CT-2000-00090 (CLIWOC). The authors thank David Parker for his many suggestions during the preparation of this paper. Scott Woodruff is thanked for providing the US Maury data of Figure 5. The CLIWOC database is accessible via Internet via http://www.ucm.es/info/cliwoc/, from which links are included to allow for consultation of the imaged logbooks.

\section{References}

CLIWOC Team: 2003, CLIWOC Multilingual Meteorological Dictionary, An English-Spanish-DutchFrench Dictionary of Wind Terms Used by Mariners from 1750-1850, KNMI publication 205, HISKLIM 5 (Available from the UK or Dutch partners).

Diaz, H., Folland, C., Manabe, T., Parker, D., Reynolds, R. and Woodruff, S. D.: 2002, 'Workshop on the advances in the use of historical marine climate data', WMO Bulletin 51 377-380 (also in CLIVAR Exchanges 25 71-73 (2002)).

Elms, J. D., Woodruff, S. D., Worley, S. J., and Hanson, C.: 1993, 'Digitizing historical records for the comprehensive ocean-atmosphere data set (COADS)', Earth System Monitor 4(2), $4-10$.

Frydendahl, K., Frich, P., and Hansen, C.: 1992, Danish weather observations 1675-1715, Danish Meteorological Institute, Technical Report 92-3.

García-Herrera, R., Wheeler, D. A., Können, G. P., Koek, F. B., Jones, P. D., and Prieto, M. R.: 2004, CLIWOC final report, UE contract EVK2-CT-2000-00090. Available from Dto. Física de la Tierra II, Facultad de Físicas, Universidad Complutense de Madrid, Ciudad Universitaria, 28040 Madrid, Spain.

García-Herrera, R., Wilkinson, C., Koek, F. B., Prieto, M. R., Calvo, N., and Hernández, E.: 2005, 'Description of logbooks', Clim. Change this volume.

Houghton, J. T., Ding, Y., Griggs, D. J., Noguer, M., van der Linden, P. J., and Xiaosu, D.: 2001, Climate Change 2001: The Scientific Basis. Contribution of Working Group I to the Third Assessment Report of the Intergovernmental Panel on Climatic Change (IPCC), Cambridge University Press, UK.

Jones, P. D.: 1994, 'Hemispheric surface temperature variations: A reanalysis and an update to 1993', J. Clim. 7, 1794-1802. 
Jones, P. D. and Salmon, M.: 2005, 'Preliminary reconstructions of the North Atlantic Oscillation and the Southern Oscillation index from wind strength measures taken during the CLIWOC period', Clim. Change, this volume.

Koek, F. B. and Können, G. P.: 2005, 'Determination of terms for wind force/present weather. The Dutch case', Clim. Change, this volume.

Können, G. P. and Koek, F. B.: 2005, 'Description of the CLIWOC database', Clim. Change this volume.

Middleton, W. E. K.: 1964, The History of the Barometer, John Hopkins University Press, Baltimore, MD, pp. 489, reprinted in 1994 by Baros Books, Wiltshire UK.

Parker, D., Kent, E., Woodruff, S., Dehenauw, D., Harrison, D. E., Manabe, T., Mietus, M., Swail, V., and Worley, S.: 2004, The Second JCOMM Workshop on Advances in Marine Climatology. WMO Bulletin 53(2), 157-159.

Prieto, M. R., et al.: 2005, 'Determination of terms for wind force/present weather. The Spanish and French cases', Clim. Change, this volume.

Prieto, M. R., García-Herrera, R., and Hernández, E.: in press, 'Early records of icebergs in the southern ocean from Spanish documentary sources', Clim. Change.

Quetelet, A.: 1854, 'Rapport de la Conférence, tenue à Bruxelles, sur l'invitation du gouvernement des Etats-Unis d'Amérique, à l'effet de s'entendre sur un système uniform d'observations météorologiques à la mer', Annuaire de l'Observatoire Royal de Belgique 21, 155-167.

Wallbrink, H., Koek, F. B., Können, G. P., and Brandsma, T.: 2003, 'Sea-level pressure observations from Dutch ships 1854-1938 incorporated in COADS Release 1c climatology', Int. J. Climatol. 23, 471-475.

Wheeler, D. A. and Wilkinson, C.: 2005, 'Understanding wind force and weather terms from ships' logbooks: The English case', Clim. Change, this volume.

Wheeler, D. A.: 2005, 'An assessment of CLIWOC data quality and reliability', Clim. Change, this volume.

Wilkinson, C., et al.: 2005, 'Other potential usages including non-climatic ones', Clim. Change, this volume.

WMO: 1947, Comité Météorologique International, Procès-Verbaux de la Session de Paris, 1-12 Juillet 1946, WMO, Publication No. 55, Lausanne.

Woodruff, S. D., Slutz, R. J., Jenne, R. L., and Steurer, P. M.: 1987, 'A comprehensive ocean atmosphere data set', Bull. Amer. Meteor. Soc 68, 1239-1250.

Woodruff, S. D., Diaz, H. F., Elms, J. D., and Worley, S. J.: 1998, 'COADS Release 2 data and metadata enhancements for improvements of marine surface flux fields', Phys. Chem. Earth 23, 517-527.

Woodruff, S. D.: 2001, COADS updates including newly digitized data and the blend with the UK Meteorological Office Marine Data Bank and Quality control in recent COADS updates. Proceedings of Workshop on Preparation, Processing and Use of Historical Marine Meteorological Data, Tokyo, Japan, 28-29 November 2000, Japan Meteorological Agency and the Ship Ocean Foundation, 9-13 and 49-53.

Woodruff, S. D. (ed).: 2004, Archival of data other than in IMMT format. Proposal: International Maritime Meteorological Archive (IMMA) Format. Update of JCOMM-SGMC-VIII/Doc. 17, Asheville, NC, USA 10-14 April 2000. Available from http://www.cdc.noaa.gov/coads/edoc/imma/imma.pdf.

Woodruff, S. D., Diaz, H. F., Worley, S. J., Reynolds, R. W., and Lubker, S. J.: 2005, 'Early ship observational data and ICOADS', Clim. Change this volume.

Worley, S. J., Woodruff, S. D., Reynolds, R. W., Lubker, S. J., and Lott, N.: 2005, 'ICOADS Release 2.1 data and products', Int. J. Climatol. 25, 823-842.

(Received 14 June 2004; in revised form 22 April 2005) 